\title{
Perancangan Subrutin Master pada Sistem Waktu Perkuliahan
}

\author{
Riandini, Is Hendarto \\ Jurusan Teknik Elektro \\ Politeknik Negeri Jakarta \\ Kampus Baru UI Depok, Indonesia \\ riandini@gmail.com, is.hendarto@gmail.com
}

Diterima: 17 September 2015. Disetujui: 20 Oktober 2015. Dipublikasikan: November 2015

\begin{abstract}
Abstrak - Subrutin master pada sistem waktu perkuliahan merupakan program penunjang sistem yang berbasis Mikrokontroler. Sistem waktu perkuliahan sendiri merupakan sebuah sistem yang diharapkan dapat menciptakan kedisiplinan waktu kuliah pada Program Studi Teknik Elektronika Industri, dimana sistem tersebut dikontrol dan dimonitor melalui PC dengan menggunakan LabVIEW8.5 yang dihubungkan juga ke Mikrokontroler ATMega8535 melalui komunikasi serial RS232. Perancangan subrutin master dimaksudkan agar Mikrokontroler dapat bekerja sendiri (stand-alone) yaitu tetap menampilkan jam dan mengontrol loudspeaker walaupun sudah tidak ada komunikasi dengan LabVIEW. Prinsip kerjanya adalah subrutin program master akan dieksekusi oleh Mikrokontroler apabila dalam waktu kurang dari 2 detik tidak ada komunikasi dari LabVIEW dan segera mengambil data terakhir dari RTC DS1307 yang telah di-set oleh LabVIEW sesaat sebelum komunikasinya terputus.
\end{abstract}

Kata Kunci: subrutin program master, stand-alone. mikrokontroler ATMega8535, RTC DS130, LabVIEW.

\section{PENDAHULUAN}

Waktu adalah sesuatu yang berharga bagi manusia. Dengan mengatur waktu kita dapat menjalankan aktivitas dengan teratur. Di samping waktu yang terencana dengan baik, informasi yang akurat juga menunjang kita dalam menjalankan segala aktivitas. Dalam sistem perkuliahan Politeknik Negeri Jakarta khususnya Program Studi Teknik Elektronika Industri masih terdapat kendala yang berhubungan dengan waktu seperti jadwal kuliah yang masih konvensional yaitu ditulis pada selembar kertas dan ditempel pada ruang-ruang kelas serta tidak ada tanda untuk pergantian jam kuliah.

Maka dirancang sebuah sistem Sistem Waktu Perkuliahan yang diharapkan dapat membantu memudahkan dalam memonitor jadwal perkuliahan di Program Studi Elektronika Industri. Proses kontrol dan monitoring sistem ini dilakukan oleh program aplikasi LabVIEW 8.5 dan Mikrokontroller ATMega8535 yang saling berhubungan.
Mikrokontroler diprogram agar dapat bekerja sendiri (stand-alone) dengan tetap menampilkan display jam dan mengontrol speaker. Permasalahan mendasar dalam perancangan subrutin master pada sistem waktu perkuliahan ini adalah bagaimana mengeset dan mengambil data dari RTC dan menampilkan hasil pengolahan data pada display seven-segment. Terutama saat tidak ada komunikasi dengan LabVIEW yaitu Mikrokontroler akan tetap menampilkan jam pada display dengan mengambil data jam, menit dan detik dari RTC serta mengatur on/off dari indikator (loud speaker).

\section{LANDASAN TEORI}

Dalam mengkomunikasikan antara LabVIEW dengan Mikrokontroler dapat menggunakan komunikasi serial dan paralel, dan dalam sistem ini digunakan komunikasi serial RS232 [1].

Mikrokontroler mempunyai kemampuan untuk bekerja sendiri (stand-alone) dengan program yang ada di dalamnya walaupun sedang tidak ada koneksi dengan device lain, dalam hal ini adalah LabVIEW 8.5. Mikrokontroler secara otomatis akan mengambil alih tugas LabVIEW yaitu mengatur on/off dari indikator Loud Speaker [2]. Diagram blok sistem waktu perkuliahan ditunjukkan pada Gambar 1.

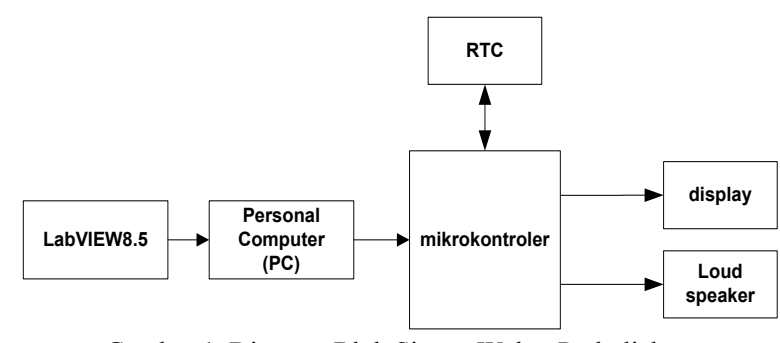

Gambar 1. Diagram Blok Sistem Waktu Perkuliahan

\section{A. RTC DS1307}

RTC DS1307 adalah serial RTC (Real Time Clock) keluaran MAXIM dari Dallas Semiconductor Co. RTC seri ini telah dilengkapi dengan BinaryCoded Decimal (BCD) untuk pembacaan kalender maupun jam serta memiliki 56 byte NV SRAM (Non- 
volatile SRAM) sehingga apabila catu daya terputus, data yang terdapat di dalamnya tidak terhapus.[3] Didalam RTC tersebut telah disediakan data berupa detik, menit, jam, hari, tanggal, bulan, serta tahun. RTC DS1307 dapat bekerja dalam dua mode yaitu:

1. Mode Slave Penerima (Master Menulis Pada Slave)

2. Mode Slave Pengirim (Master Membaca Dari Slave)

\section{B. Penampil Seven Segment}

Penampil seven-segment memiliki 7 LEDs dalam satu paket penampil angka. Setiap LED dapat diaktifkan masing-masing untuk menunjukkan segment dari suatu digit. Secara umum segment ditandai dengan huruf a-g. Terdapat 2 tipe penampil seven-segment, yaitu common anode dan common cathode. [4]

\section{ANALISIS DAN PERANCANGAN}

\section{A. Deskripsi Sistem}

Perancangan Subrutin Program Mikrokontroler Master memiliki fungsi mengolah data dari RTC pada saat tidak ada koneksi dengan LabVIEW.

- Minimum Sistem: Minimum sistem yang digunakan adalah Mikrokontroler jenis ATMega8535 sebagai slave sekaligus master apabila PC off.

- Input Sistem: LabVIEW 8.5 dan RTC DS1307

- Output Sistem: 4 digit seven-segment common anoda 12VDC, 2 buah led $10 \mathrm{~mm}$ dan 2 buah loud speaker.

\section{B. Rangkaian Pengatur}

Rangkaian pengatur disini maksudnya adalah Mikrokontroler yang aktif tanpa ada komunikasi dengan LabVIEW. Input dari rangkaian pengatur didapat dari RTC DS1307 yang menyimpan data terakhir dari LabVIEW.

Mikrokontroler melakukan komunikasi dengan RTC menggunakan komunikasi I2C, Mikrokontroler sebagai master sedangkan RTC sebagai slave. Mikrokontroler bertugas hanya membaca data dari RTC dan ditampilkan pada display seven-segment yang sebelumnya melalui dekoder 74LS247 terlebih dahulu [5].

Selain membaca nilai data RTC, Mikrokontroler juga bertugas untuk menghidupkan dan mematikan indikator berupa Loud Speaker. Gambar 2 adalah diagram blok dari rangkaian pengatur.

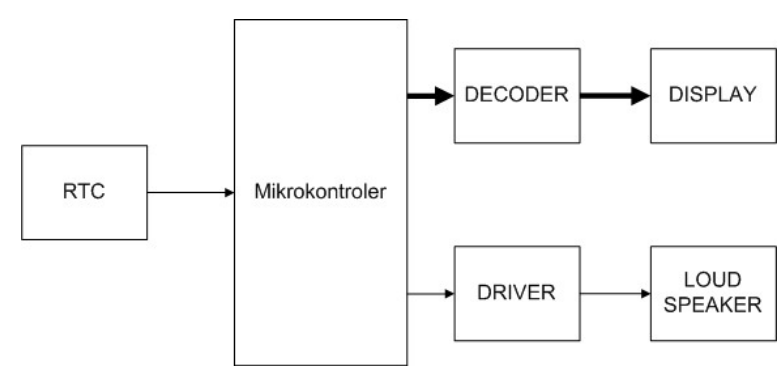

Gambar 2. Diagram Blok Sistem Rangkaian Pengatur

\section{Perancangan Algoritma}

Pada awal sistem diaktifkan, sistem akan memastikan apakah ada komunikasi dengan LabVIEW atau tidak selama 2 detik. Apabila tidak ada maka Mikrokontroler akan mengambil data dari RTC. Data pada RTC merupakan data terakhir yang dikirim oleh LabVIEW kepada Mikrokontroler dan di-set pada RTC. Kemudian Mikrokontroler akan menampilkan data jam dan menit pada display sevensegment dan mengecek apakah waktu pada RTC sudah sama dengan waktu untuk membunyikan loud speaker[6]. Apabila sudah sama maka Mikrokontroler akan mengaktifkan driver relay dc. Namun apabila saat Mikrokontroler sedang mengaktifkan relay dan kemudian ada interrupt dari LabVIEW, maka Mikrokontroler akan menon-aktifkan relay sehingga loud speaker tidak aktif. Kondisi itu akan terus berulang hingga sistem dinon-aktifkan. Aktif relay hanya pada hari Senin hingga Jumat sedangkan Sabtu dan Minggu relay tidak akan aktif. Algoritma dari sub-rutin tampak seperti di Gambar 3.

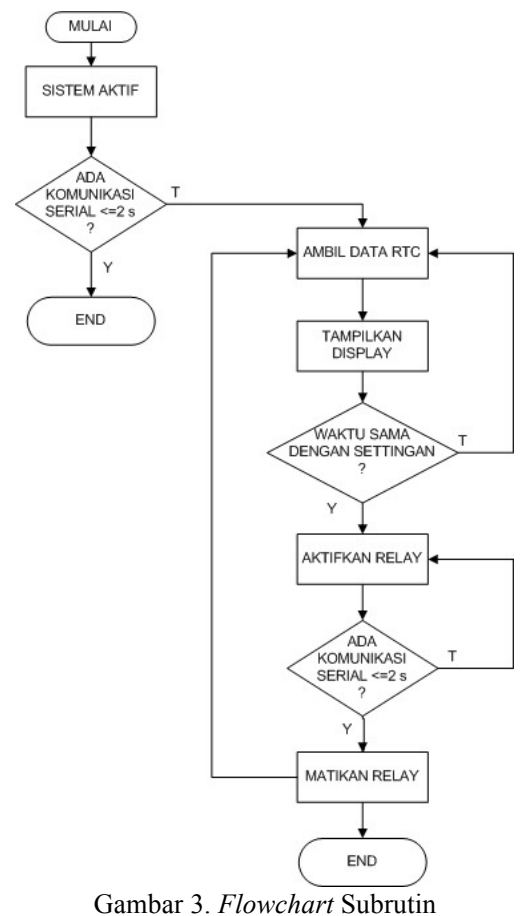




\section{Perancangan Pengambilan Data RTC}

Pengambilan data RTC menggunakan komunikasi I2C, Mikrokontroler sebagai device master dan RTC sebagai device slave. Jalur SDA dan SCL menggunakan 2 bit pada Mikrokontroler yaitu pada PORTD.2 dan PORTD.3. Saat sistem aktif dan tidak ada komunikasi, Mikrokontroler membangkitkan sinyal start pada jalur SDA dan RTC membalas dengan memberikan sinyal acknowledge. Mikrokontroler membaca nilai dari alamat detik, menit, jam serta hari untuk dibaca dan RTC mengirimkan data-data yang diminta Mikrokontroler tersebut. Alamat-alamat tersebut disimpan oleh RTC dalam variabel jam, menit, detik serta hari. Saat sistem mati dan dihidupkan kembali, Mikrokontroler akan melakukan hal tersebut kembali, sedangkan pada saat sistem mati, RTC akan tetap aktif karena disediakan baterai backup $3 \mathrm{~V}$ sehingga saat Mikrokontroler membaca kembali, maka data waktu yang dikirim RTC tidak di-set dari ulang melainkan dilanjutkan dengan data yang terus dihitung oleh RTC. Nilai jam dari RTC langsung ditampilkan pada display tanpa memasukkannya kembali ke dalam variabel lain. Setelah Mikrokontroler selesai membaca data, Mikrokontroler mengirimkan sinyal stop untuk mengakhiri pengambilan data. Flowchart dari perancangan ini dapat dilihat pada Gambar 4.

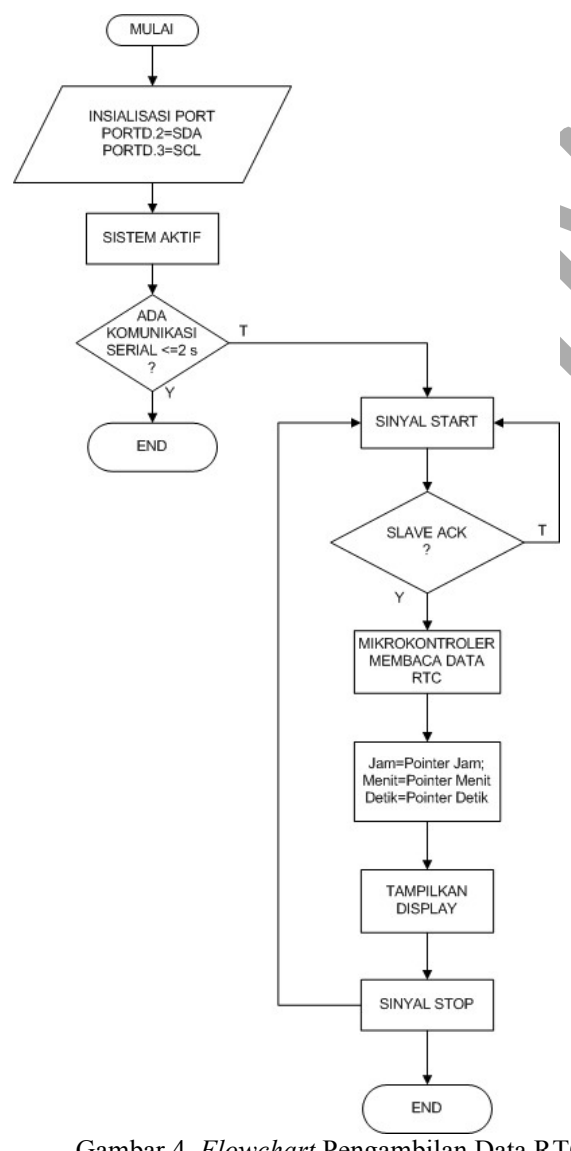

Gambar 4. Flowchart Pengambilan Data RTC

\section{E. Perancangan Display dan Indikator}

Data pada display di dapat dari nilai data jam, menit, detik dan hari dari RTC. Data yang di tampilkan pada display hanya nilai jam dan menit, sedangkan untuk detik tidak ditampilkan. Untuk tampilan detik digunakan 2 buah led yang diparalel dan mendapatkan masukan dari RTC DS1307 yang mempunyai SQW/OUT. Pin SQW/OUT dapat diprogram dari Mikrokontroler untuk mengatur keluaran frekuensinya. Dalam sistem ini, pin SQW/OUT di-set dengan keluaran $1 \mathrm{~Hz}$ dengan duty cycle $50 \%$.

Untuk indikator, aktif dan tidaknya bergantung dari PORTA.0 yang merupakan input data untuk driver relay dc. Driver aktif apabila menerima logika tinggi serta bergantung dari hari dan jam yang diatur pada program. Selama pengaktifan relay, apabila terdapat interrupt dari komunikasi LabVIEW, maka secara otomatis relay akan off. Gambar 5 adalah diagram alur untuk proses penampilan display dari Mikrokontroler.

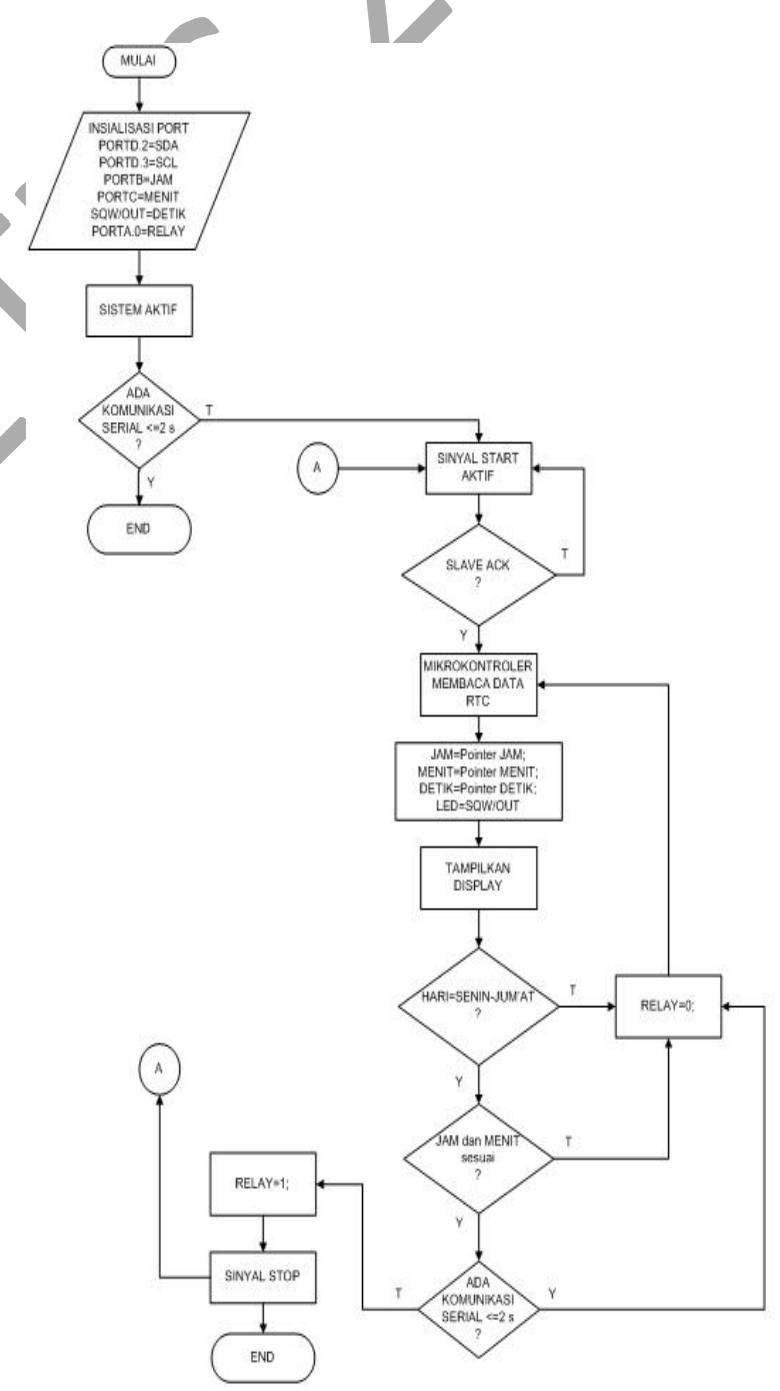

Gambar 5. Flowchart Penampil Display dan Indikator 


\section{HASIL DAN PEMBAHASAN}

Pengujian dilaksanakan untuk menguji dan mengetahui hasil perancangan sistem berjalan sesuai dengan yang diinginkan atau tidak. Apabila terjadi kesalahan atau penyimpangan pada sistem, maka akan dianalisa dan dicarikan solusi untuk mengatasinya sehingga sistem tersebut dapat berjalan sesuai dengan yang diinginkan. Pengujian menitikberatkan pada pembacaan data dari RTC saat tidak ada komunikasi.

\section{A. Tujuan Pengujian}

a. Mengetahui data setelah tidak ada komunikasi dengan LabVIEW.

b. Mengetahui apakah data akan dilanjutkan dengan data terakhir saat tidak ada koneksi dengan LabVIEW.

Target Pengujian: Data terakhir yang diterima oleh Mikrokontroler.

Konfigurasi Pengujian: Konfigurasi pengujian difokuskan pada pembuatan program saja.

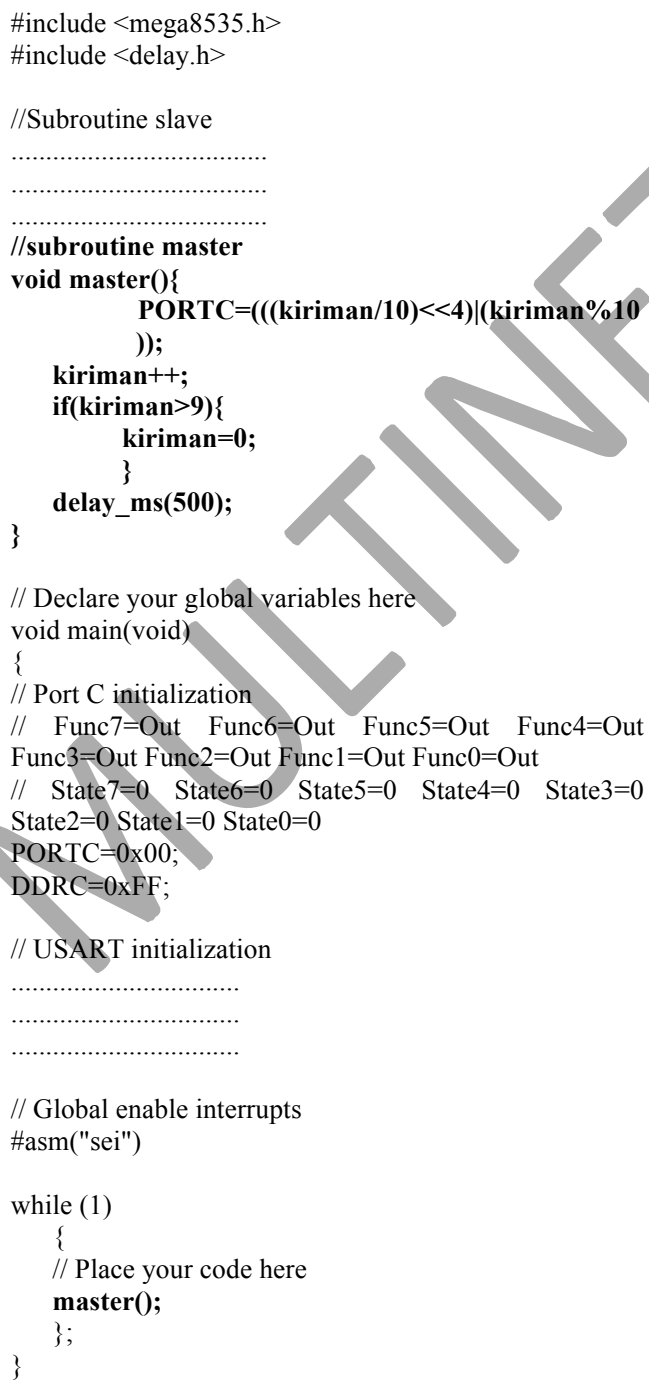

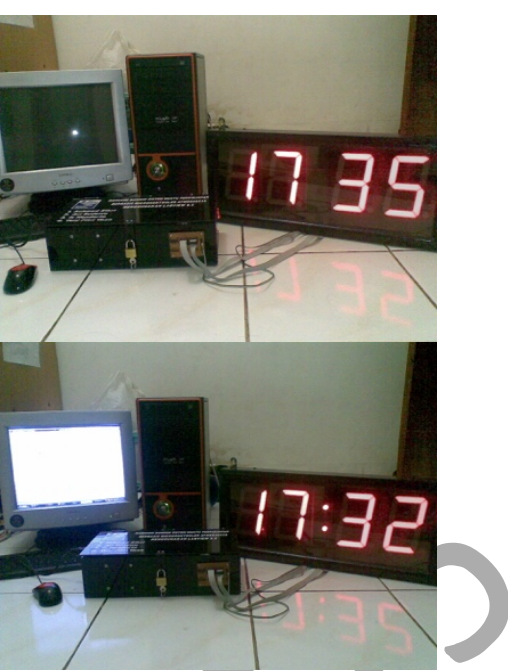

Gambar 6. Tampilan Display Sistem (Kiri: Saat Terkoneksi dengan LabVIEW, Kanan: Saat StandAlone)

Gambar 7 menunjukkan data hasil pengujian.

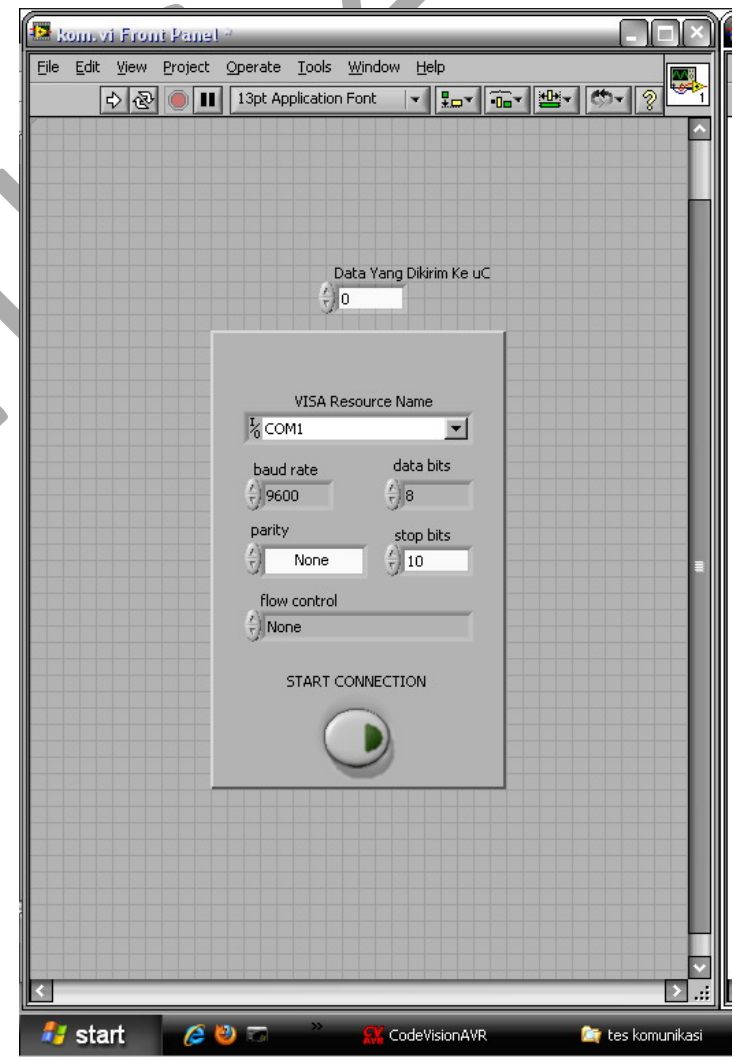

Gambar 7. Tampilan Labview saat Tidak Ada Komunikasi

\section{B. Analisa Data Hasil Pengujian}

Pada Gambar 6, terlihat bahwa apabila Mikrokontroler tidak terkoneksi dengan LabVIEW, maka data terakhir yang diterima Mikrokontroler akan dilanjutkan menjadi up-counter. Dari hasil pengujian data terakhir yang dikirim oleh LabVIEW adalah 0 , dan saat komunikasinya diputus, Mikrokontroler 
melanjutkan dengan meng-up-counter menjadi 1 sampai 9.

Selain itu dapat dilihat dari Gambar 7 bahwa display sistem saat terkoneksi dengan LabVIEW dan saat stand-alone tetap aktif.

\section{KESIMPULAN}

Berdasarkan tujuan dari perancangan subrutin master pada sistem waktu perkuliahan, dapat disimpulkan bahwa subrutin ini mampu mengeksekusi Mikrokontroler agar dapat bekerja sendiri (stand-alone) atau dengan kata lain dapat mengontrol dirinya sendiri. Selain itu Mikrokontroler tersebut tetap dapat mengendalikan agar display menampilkan jam dan mengatur aktif atau tidaknya speaker walaupun tanpa ada komunikasi dengan LabVIEW. Hal ini dilakukan dengan cara mengambil data yang diperlukan dari register-register alamat yang terdapat pada RTC DS1307 menggunakan komunikasi serial I2C.

\section{REFERENSI}

[1] Abidin, Zainal. 2009. Eksperimen Mikrokontroler. Surabaya

2] Hendi Handian Rachmat dkk. 2011. Pengembangan Sistem Remote Control untuk Setting Waktu pada Sistem Automatic Time $S$ witch (ATS) Berbasis Real Time Clock (RTC) DS1307 untuk Saklar Lampu. Jurnal Rekayasa (C LPPM Itenas I No.1 I Vol. XV Institut Teknologi Nasional Januari Maret 2011

[3] Heryanto, M. Ary dan Adi P. Wisnu. 2008. Pemrograman Bahasa C untuk Mikrokontroler ATMEGA8535. ANDI: Yogyakarta.

[4] I Gusti Agung Putu Raka Agung dkk. 2013. Rancang Bangun Bel Sekolah Otomatis Berbasis Mikrokontroler Avr Atmega8, Teknologi Elektro, Vol.10 No 2 Juli -Desember 2011 .

[5] Texas Instruments Incorporated, SN5446A, '47A, '48, SN54LS47, 'LS48, 'LS49, SN7446A, '47A, '48, SN74LS47, 'LS48, 'LS49, BCD-TO-SEVENSEGMENT DECODERS/DRIVERS, 1999

[6] Datasheet DS 1307, https://datasheets.maximintegrated.com /en/ds/DS1307.pdf, 22 April 2011 